\title{
Inhibition of growth and induction of apoptosis in human breast cancer by transfection of gef gene
}

\author{
H Boulaiz', J Prados', C Melguizo², ÁM García ${ }^{3}$, JA Marchal ${ }^{4}$, JL Ramos ${ }^{5}$, E Carrillo ${ }^{4}$, C Vélez ${ }^{2}$ and A Aránega*,I \\ 'Basic Cardiovascular Research Section, Department of Morphological Sciences, School of Medicine, University of Granada, E-I80 I 2 Granada, Spain; \\ ${ }^{2}$ Department of Health Sciences, University of Almería, E-04002 Almería, Spain; ${ }^{3}$ Clinical Analysis Service, Virgen de las Nieves Hospital, E-I 8014 \\ Granada, Spain; ${ }^{4}$ Department of Health Sciences, University of Jaén, E-2307I Jaén, Spain; ${ }^{5}$ Zaidín Experimental Station, CSIC, E-I 8008 Granada, Spain
}

The gef gene has cell-killing functions in Escherichia coli. To evaluate the feasibility of using this gene as a new strategy for cancer therapy, we transfected it in MCF-7 cells derived from breast cancer (MCF-7TG). The gef gene was cloned in a pMAMneo vector under the control of a mouse mammary tumour virus promoter, inducible by dexamethasone (Dex), and was transfected with liposomes. After selection and induction, expression of the gef gene was confirmed by reverse transcription-polymerase chain reactions (RT-PCR) and Western blot. Cell viability was determined with a haemocytometre and the sulphorodamine B colorimetric assay, and the cell cycle was studied by propidium iodide (PI) staining. Annexin V-FITC and PI assays were used to evaluate apoptosis, which was confirmed by electron microscopy. In comparison with MCF-7 parental cells and MCF-7 cells transfected with an empty vector, MCF-7TG cells induced with Dex showed a significant decrease in proliferation rate, which was associated with evidence of apoptosis. Morphological findings confirmed apoptosis and showed a typical pattern of mitochondrial dilation. Furthermore, the cell cycle was characterised by premature progression from $G_{1}$ to $S$ phase and $G_{2}$ delay. Our results show that the gef gene was able to decrease proliferation in a breast cancer cell line, and induce apoptosis. These findings suggest that the gef gene is a potential candidate for tumour therapy.

British Journal of Cancer (2003) 89, 192-198. doi:10.1038/sj.bjc.6601064 www.bjcancer.com

(c) 2003 Cancer Research UK

Keywords: gene therapy; gef gene; breast cancer; apoptosis

There is an urgent need to develop novel systemic strategies for patients with cancer. Gene transfer to tumour cells offers new possibilities for cancer therapy based on the genetic modification of tumour cells (Marchisone et al, 2000). Strategies based on putative killer-suicide genes such as Herpes simplex virus thymidine kinase and cytosine deaminase indirectly induce cytotoxicity in mammalian cells. In both systems, the enzymes encoded by suicide genes convert a nontoxic prodrug (ganciclovir and 5-fluorocytosine, respectively) into a toxic metabolite (Shangara et al, 2000), which causes DNA chain termination or inhibits RNA and DNA synthesis during the $S$ phase of the cell cycle (Greco and Dachs, 2001). However, problems with the release of toxic metabolites have led to the development of new strategies for cancer therapy based on the use of toxic genes, which do not need prodrugs to be effective in tumour cells. These promising strategies aim to act directly on the cell cycle and cell proliferation (Pietersen et al, 1999; Martin et al, 2000; Pützer et al, 2000). The expression of these genes is controlled by a significant number of tumour tissue-selective promoters and enhancer elements that have demonstrated their potential for use in gene therapy. However, promoters with specific actions in different cancers will

*Correspondence: A Aránega; E-mail: hboulaiz@ugr.es Received II November 2002; revised 28 April 2003; accepted 29 April 2003 need to be selected to realise the potential of this new therapeutic approach (Hart, 1996; Shillitoe et al, 2000).

In this context, a number of genes have been identified as members of a gene family that encodes homologous cell-killing functions in Escherichia coli (Gerdes et al, 1990). In a member of this family, named the gef gene (isolated from the chromosome of E. coli) (Poulsen et al, 1991), the killing function is mediated by a membrane protein of about 50 amino acids, which induces the arrest of cellular respiration; subsequently, the cells undergo morphological changes (characteristic 'ghost' cells) and become nonviable (Poulsen et al, 1992). Previous studies have demonstrated that Gef is anchored in the cytoplasmic membrane by the $\mathrm{N}$-terminal part of the protein, whereas the $\mathrm{C}$-terminal part is localised in the periplasm. Mutagenesis experiments with Gef showed that the periplasmic portion of the gene encodes the toxic domain, and that dimerisation is not essential for the toxic effect (Poulsen et al, 1991). This effect was expressed in analyses with suicide cassettes consisting of members of the gef gene family in combination with inducible promoters (Molin et al, 1993). This gene, currently being studied to determine its ability to control bacterial population death (Ronchel and Ramos, 2001), may be a new candidate for therapeutic applications.

In this study, we used a mammalian expression vector containing the gef gene under the control of the mouse mammary tumour virus (MMTV) promoter, inducible by dexamethasone (Dex), to evaluate the expression, in vitro, of this gene in tumoral MCF-7 cells derived from breast cancer. We found that 
expression of the gef gene in these tumoral cells significantly decreased growth and induced apoptosis. These results suggested the feasibility of using a gef gene system as a new strategy for cancer therapy.

\section{MATERIALS AND METHODS}

\section{Construction of gef expression vector}

The gef gene (kindly provided by the Zaidín Experimental Station, CSIC, Granada, Spain) was subcloned into the mammalian expression vector pMAMneo (Clontech, Palo Alto, CA, USA), which allows Dex-inducible expression of cloned inserts. The fulllength gef insert, flanked at $3^{\prime}$ and $5^{\prime}$ by a XhoI and an NheI restriction site, respectively, was amplified by polymerase chain reaction (PCR) with routine DNA manipulation (Sambrook et al, 1989). The PCR product was double-digested with NheI and XhoI and inserted into pMAMneo, and this construction was used to transform E. coli. The cells were plated onto Luria-Bertani broth plates containing ampicillin. A single insert-positive clone (with pMAMneo-gef) was selected for transfection into MCF-7 cells after analysis by restriction-enzyme digestions and PCR to establish reading frame orientation and sequence fidelity.

\section{Cell culture and stable transfection}

The human breast cancer MCF-7 cell line was kindly provided by Dr $\mathrm{N}$ Olea of the Sánchez Mora Tumoral Biology Institute, University Hospital of Granada. MCF-7 cells were grown at $37^{\circ} \mathrm{C}$ in an atmosphere containing $5 \% \mathrm{CO}_{2}$, with Dubelcco's modified Eagle's medium (DMEM) (Gibco, Grand Island, NY, USA) supplemented with $10 \%$ heat-inactivated foetal bovine serum (FBS) (Gibco), 2\% L-glutamine, $2.7 \%$ sodium bicarbonate, $1 \%$ Hepes buffer, $40 \mathrm{mgl}^{-1}$ gentamicin and $500 \mathrm{mg} \mathrm{ampicillin}^{-1}$. To isolate stably transfected cells, 2 days before transfection confluent MCF-7 cells were split 1:5 into six-well plates, yielding approximately $70 \%$ confluence on the day of transfection. The cells were washed with culture medium, then transfected using $6 \mu \mathrm{l} \mathrm{FuGENE}$ 6 reagent (Roche Diagnostic, Barcelona, Spain) with $1.8 \mu$ g per well of pMAMneo empty vector or pMAMneo-gef in $2 \mathrm{ml}$ of culture medium. After $48 \mathrm{~h}$, the medium was replaced with selective medium: DMEM, $10 \% \mathrm{FBS}, 500 \mu \mathrm{g} \mathrm{ml}^{-1}$ geneticin G418 (Sigma, St Louis, MO, USA), and resistant clones were selected. Single clones of stably transfected cells, isolated by limiting dilution in 96-well plates, were transferred to individual flasks and cultured in medium containing $300 \mu \mathrm{g} \mathrm{ml}^{-1} \mathrm{G} 418$. For the present study, a clone named MCF-7TG (MCF-7 cells transfected with pMAMneogef gene) was used. Integrity of the transfected vector sequence in the MCF-7 cells was analysed by PCR. Genomic DNA was extracted from MCF-7 parental and MCF-7TG cells with the Magic ${ }^{\text {TM }}$ Megapreps DNA Purification System (Promega, Madison, WI, USA) according to the manufacturer's instructions. Total DNA (250 ng) was diluted to $50 \mu \mathrm{l}$ in a mixture with a final concentration of $250 \mu \mathrm{M} \mathrm{dNTP,} 100 \mathrm{ng}$ of each primer, $5 \mu \mathrm{l}$ PCR buffer and 2.5 U Taq polymerase (Roche Diagnostic). The primers used were Gef 3: 5'GAAGCAGCATAAGGCGATG3' and Gef 4: 5'CTCGG ATTCGTAAGCCGTG3'. Polymerase chain reaction $\left(94^{\circ} \mathrm{C}\right.$ for $5 \mathrm{~min}$, $61^{\circ} \mathrm{C}$ for $1 \mathrm{~min}$ and $72^{\circ} \mathrm{C}$ for $1 \mathrm{~min}$ ) was carried out for 32 cycles with a final elongation step of $72^{\circ} \mathrm{C}$ for $10 \mathrm{~min}$. For analysis, $10 \mu \mathrm{l}$ of the reaction product was run on a $2 \%$ agarose gel, visualised by ethidium bromide staining and photographed under ultraviolet light.

\section{Reverse transcription (RT) - PCR and Western blot analysis}

For RT-PCR analysis, total RNA was extracted from MCF-7 and MCF-7TG cells after $24 \mathrm{~h}$ of induction with Dex with an RNA extraction kit (Promega) according to the manufacturer's instructions. RNA ( $1 \mu \mathrm{g})$ from each cell line was then reverse-transcribed into cDNA using a first-strand cDNA synthesis kit (Promega). PCR of the RT was done and analysed under the same condition as detailed above, using $5 \mu \mathrm{l}$ of the RT products. The integrity of RNA was assessed by amplification of $\beta$-actin mRNA using $5^{\prime}$-primer nt 1854-1873 and $3^{\prime}$-primer nt 2151-2170 (Prados et al, 1998). For Western blot analysis, we used a polyclonal antibody against the Gef protein that was produced at the Technical Service of the University of Seville (Seville, Spain) by immunising rabbits with a 25 amino-acid synthetic peptide (carboxy terminus of the protein) predicted from the DNA sequence of the gef gene (Poulsen et al, 1991). Total proteins were obtained from MCF-7 and MCF-7TG cells after induction for $24 \mathrm{~h}$ with Dex. The cells were harvested and lysed in sample buffer consisting of $62.5 \mathrm{~mm}$ Tris $\mathrm{HCl}$ (pH 6.8), $10 \%$ glycerol, $2 \%$ SDS, 5\% 2-mercaptoethanol, $0.5 \%$ bromophenol blue and $100 \mathrm{~mm}$ dithiothreitol. Proteins were separated on $15 \%$ SDS-polyacrylamide gels and electroblotted onto Immobilon-Pmembranes (Millipore, Bedford, MA, USA). Blocking, washing, and incubations of the blotted nitrocellulose membranes were carried out as described (Prados et al, 1995). The polyclonal antibody against the Gef protein was diluted 1:10, and positivity was detected with an anti-rabbit IgG peroxidase conjugate (Sigma).

\section{Cell proliferation assays}

MCF-7 and MCF-7TG cells $\left(25 \times 10^{3}\right)$ were plated into six-well plates under the culture conditions detailed above. After $24 \mathrm{~h}$, cells were fed with fresh medium and treated with $1 \mu \mathrm{m}$ Dex (Sigma) to induce the promoter activity of MMTV. In the control groups, cells were not treated with dexamethasone. To verify that Dex had no effect on cell growth, MCF-7 parental cells were also treated with Dex. The cultures were fed with fresh medium with or without Dex every alternate day up to the end of the experiment; each treatment and time point was run in four plates. After 1, 2, 4, 6, 10 and 15 days of treatment, cells were trypsinised, collected, and counted with a haemocytometre. Trypan blue dye exclusion was used to determine cell viability. The same experiment was performed using the sulphorodamine-B (SRB) colorimetric assay as described previously (Villalobos et al, 1995), with a Titertek Multiscan apparatus (Flow, Irvine, CA, USA) at $492 \mathrm{~nm}$. We evaluated linearity of the colorimetric results with cell number for each MCF7 cell stock before each cell growth experiment. MCF-7 cells transfected with pMAMneo empty vector were used in the proliferation assay as a control.

\section{Apoptosis detection by staining with annexin V-FITC and propidium iodide (PI)}

The Annexin V-FITC Apoptosis Detection Kit I (Pharmingen, San Diego, CA, USA) was used to detect apoptosis by flow cytometry. MCF-7TG cells $\left(1 \times 10^{6}\right.$ cells) were plated onto $75-\mathrm{cm}^{2}$ flasks and cultured overnight, followed by incubation with Dex for 48 and $96 \mathrm{~h}$. MCF-7 parental cells and MCF-7TG cells were harvested by phosphate-buffered saline-ethylenediamine-tetraacetic acid (PBSEDTA), washed twice in cold PBS (1.4 M NaCl, $27 \mathrm{mM} \mathrm{KCl,} 100 \mathrm{mM}$ $\mathrm{KH}_{2} \mathrm{PO}_{4} / \mathrm{K}_{2} \mathrm{HPO}_{4}, \mathrm{pH} 7.2$ ), and pelleted by centrifugation at $500 \mathrm{~g}$ for $10 \mathrm{~min}$. They were then resuspended at $10^{6}$ cells $100 \mu \mathrm{l}^{-1}$ in a binding buffer (Hepes buffer, $10 \mathrm{~mm}, \mathrm{pH}$ 7.4, $150 \mathrm{~mm} \mathrm{NaCl}, 5 \mathrm{~mm}$ $\mathrm{KCl}, 1 \mathrm{mM} \mathrm{MgCl}_{2}, 1.8 \mathrm{mM} \mathrm{CaCl}_{2}$ ), stained with annexin $\mathrm{V}$ incubation reagent $\left(1 \mu \mathrm{l}\right.$ annexin V-FITC $\left(25 \mu \mathrm{g} \mathrm{ml}^{-1}\right), 10 \mu \mathrm{l}$ binding buffer, $10 \mu \mathrm{l} \mathrm{PI}\left(50 \mu \mathrm{g} \mathrm{ml}^{-1}, 79 \mu \mathrm{l} \mathrm{H}_{2} \mathrm{O}\right)$ and incubated in the dark for $15 \mathrm{~min}$ at room temperature. Then, $500 \mu$ l binding buffer was added and the cells (10000 cells per sample) were immediately processed with a FACScan flow cytometre (Becton Dickinson, San Jose, CA, USA).

\section{Ultrastructural analysis}

Adherent and nonadherent MCF-7 parental cells and MCF-7TG cells treated with Dex during 48 and $96 \mathrm{~h}$ were fixed with $2.5 \%$ 
glutaraldehyde in $0.1 \mathrm{M}$ sodium cacodylate buffer $(\mathrm{pH} 7.4)$ for $1 \mathrm{~h}$ at room temperature. The pellet and monolayer were postfixed with $1 \%$ osmium tetroxide in 0.1 cacodylate buffer for $1 \mathrm{~h}$ at room temperature, and dehydrated in ethanol. Cells were detached from the culture vessel by rapid treatment with propylene oxide and embedded in Epon 812. After polymerisation, the plastic was removed and ultrathin sections were cut parallel and perpendicular to the surface of the flask. The sections were contrasted with uranyl acetate-lead citrate and examined in a Hitachi H7000 transmission electron microscope.

\section{Cell cycle analysis}

Cells in monolayer culture were harvested, washed twice with sample buffer $\left(100 \mathrm{mg}\right.$ glucose; $100 \mathrm{ml} \mathrm{PBS}$ without $\mathrm{Ca}^{2+}$ or $\mathrm{Mg}^{2+}$ ) and fixed in $70 \%\left(\mathrm{vol} \mathrm{vol}^{-1}\right)$ cold ethanol for up to 1 week. Cells were pelleted, washed once with sample buffer and resuspended in PI solution $\left(50 \mu \mathrm{g} \mathrm{ml}^{-1} \mathrm{PI}, 0.5 \mathrm{mg} \mathrm{ml}^{-1}\right.$ RNase in sample buffer, $\mathrm{pH}$ 7.4) for $30 \mathrm{~min}$ in the dark. Fluorescenceactivated cell sorter analysis was performed 48 and $96 \mathrm{~h}$ after induction. The data from 10000 cells per sample were collected and analysed using the Cellfit program on a FACScan flow cytometre (Becton Dickinson, San Jose, CA, USA).

\section{Statistical analysis}

All statistical analyses were carried out with the SPSS, release 7.5 (SPSS, Chicago, IL, USA). The results were compared with Student's $t$-test. All data are expressed as the mean \pm s.d. The differences were considered statistically significant at a $P$-value of $<0.05$.

\section{RESULTS}

\section{Gef protein expression in MCF-7 transfected cells}

To analyse the effect of the gef gene in tumoral cells, MCF-7 cells were transfected with the pMAMneo inducible vector containing the gef sequence. The presence and integrity of DNA from the gef gene in MCF-7 transfected cells (MCF-7TG) was assessed by PCR with genomic DNA (data not shown). The gene was expressed in cultures of MCF-7TG cells that contained Dex, but not in those without Dex. The presence of mRNA from the gef gene in MCF7TG cells was verified by RT-PCR (Figure 1). Western blot analyses were performed to determine the presence of the Gef protein in MCF-7TG cells. The results of immunoblotting with the polyclonal antibody against the Gef protein were consistent with the RT - PCR results (Figure 1).

\section{Modulation of growth pattern in MCF-7 transfected cells}

We found no significant differences in growth patterns between MCF-7 parental cells with or without Dex treatment and MCF-7 cells transfected with pMAMneo empty vector. In MCF-7 cells transfected with gef and treated with Dex, the decrease in proliferation rate in comparison with parental MCF-7 was first observed on day 4 of induction, became significant by day 6 , and was obvious by day 10 of culture (Figure 2). After $48 \mathrm{~h}$ of induction, growth was not inhibited in MCF-7TG cells compared to MCF-7 parental cells or those transfected with empty vector. At 6 days, however, MCF-7TG cells incubated with $1 \mu \mathrm{M}$ Dex showed a $34.4 \%$ decrease in growth $(P<0.001)$ with respect to control cultures. After 10 and 15 days of incubation with Dex, growth was inhibited by 75 and $67.9 \%$, respectively $(P<0.001)$.

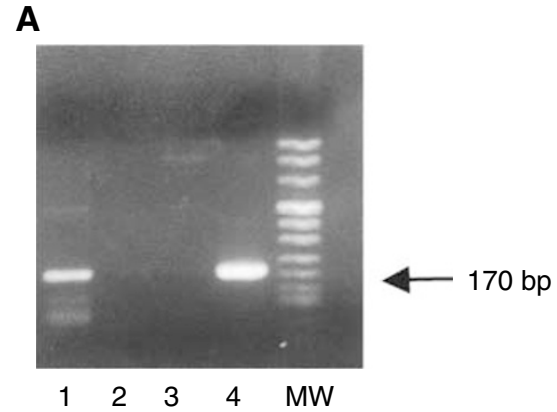

B
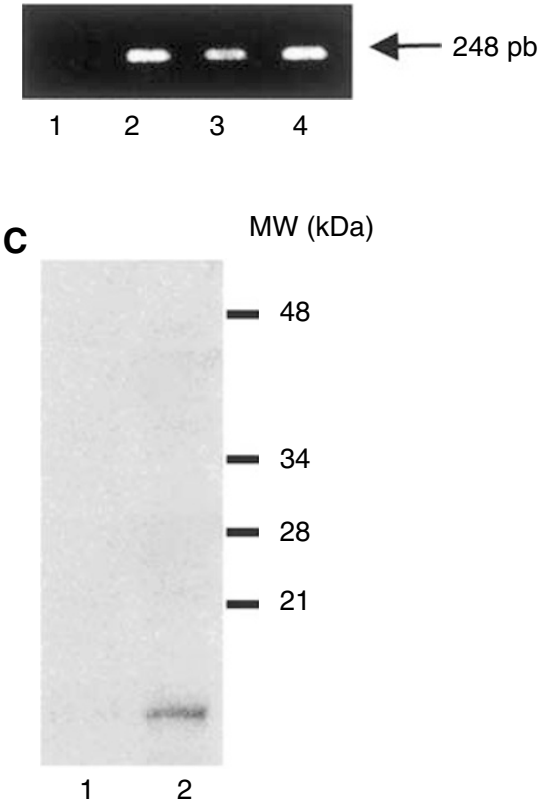

Figure I Determination of gef gene expression by RT-PCR and immunoblot. Total RNA isolated from MCF-7 parental and MCF-7TG cells was transcribed to CDNA using reverse transcriptase. Polymerase chain reaction amplification of cDNA was performed as described in Materials and Methods. The amplified PCR product of gef mRNA (a) and $\beta$-actin mRNA (b) were separated by $2 \%$ agarose gel electrophoresis and visualised with ethidium bromide. (A) Lane I, MCF-7; lane 2, MCF- 7TG lane 3, pMAMneo-gef (positive control). (B) Lane I, MCF-7; lane 2, MCF7TG; lane 3, pMAMneo-gef (negative control). (C) Western blot analyses of total proteins prepared from MCF-7 parental and MCF-7TG cells were performed with a polyclonal antibody against the Gef protein. Lane I, MCF7; lane 2, MCF-7TG. MW, molecular weight VIII.

\section{Apoptosis in MCF-7 transfected cells}

Simultaneous staining with annexin V-FITC and IP nonvital dye made it possible to distinguish between intact cells (stained negative for both annexin V-FITC and PI), early apoptosis (stained positive for annexin V-FITC and negative for PI), and late apoptosis or cell death (stained positive for both and annexin VV-FITC and PI). In our MCF-7 control culture, $80.12 \%$ of the cells were viable, $8.13 \%$ were in early apoptosis, and $9.15 \%$ were in the late or final stages of apoptosis $(P<0.001)$ (Figure 3a). Initial analysis of MCF-7 cells induced with Dex during 12 and $24 \mathrm{~h}$ showed no significant modification in relation to the control culture (data not shown). However, in MCF-7TG cells treated with Dex during $48 \mathrm{~h}, 14.32 \%$ of the cells were viable, $45.02 \%$ were in 


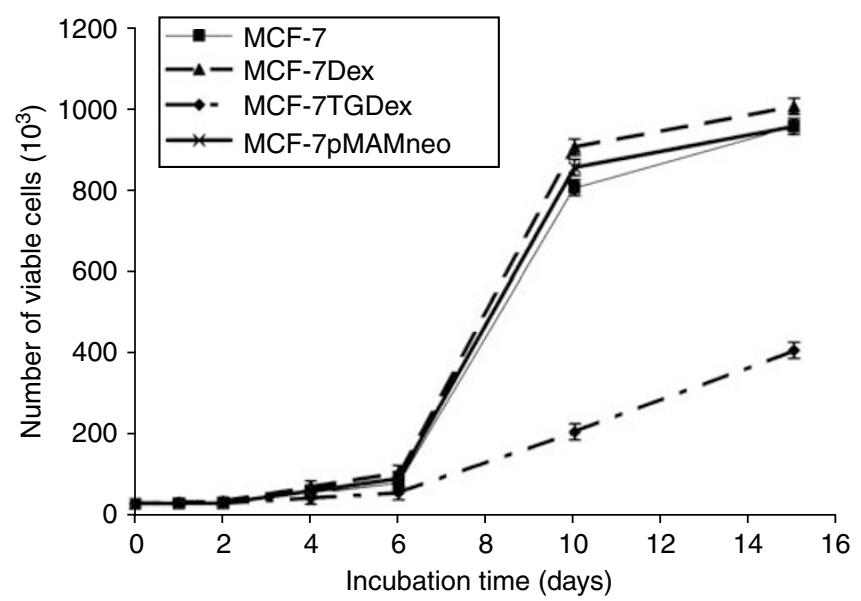

Figure 2 Determination of the effects of gef gene expression on cell proliferation. MCF-7 parental cells, MCF-7 cells induced with Dex (MCF7Dex), MCF-7TG cells induced with Dex (MCF-7TGDex) and MCF-7 cells transfected with empty vector (MCF7-pMAMneo) were seeded at $25 \times 10^{3}$ cells per dish and cultured for 15 days to determine the growth rate. Values represents means \pm s.d. of quadruplicate cultures

early apoptosis and $33.37 \%$ were in the late or final stages of apoptosis (Figure 3b). In MCF-7TG cells treated with Dex for $96 \mathrm{~h}$, the corresponding figures were 8.90, 51.81 and $36.85 \%(P<0.001)$ (Figure 3c).

\section{Morphological analysis of MCF-7 transfected cells}

Light microscopic observations showed modifications in the morphology of MCF-7TG cells after induction with Dex, characterised by rounding and loss of adherence to the flask (Figure 4). MCF-7 cells transfected with empty vector showed no morphological changes in comparison with the parental cell line. Moreover, Dex had no effect on the morphology of MCF-7 parental cells (data not shown). However, the death of MCF-7TG cells by apoptosis, which appeared after $48 \mathrm{~h}$ of Dex treatment, was clearly confirmed in ultrastructural images. In the cell nucleus, the earliest recognisable cytological changes were compaction and segregation of the chromatin at the nuclear periphery. Initially, the fine structure of this chromatin was similar to that of condensed chromatin clumps in healthy cells, with the granular appearance of cross-sectioned chromatin fibres being clearly visible (Figure $5 \mathrm{~b}$ ). At more advanced stages of apoptosis, progression of chromatin compaction was associated with redistribution of chromatin fibres, resulting in electron-dense domains of degraded homogeneousappearing chromatin. In some instances compaction and degradation of chromatin occurred in association with convolution of the nuclear profile (Figure 5c). Another important feature within the nucleus of apoptotic cells was the reorganization of ribonucleoprotein-containing structures, including the nucleolus. Compaction and marginalisation of the chromatin produced clear nucleoplasmic areas in the nucleus (Figure 5c). In the cytoplasm, we observed dilated mitochondria (Figure $5 \mathrm{~d}$ ).

\section{Modulation of cell cycle in MCF-7 transfected cells}

Parental cell cultures contained $74.98 \% \mathrm{G}_{1} / \mathrm{G}_{0}$ cells, $12.83 \%$ Sphase cells and $12.19 \% \mathrm{G}_{2} / \mathrm{M}$-phase cells. In contrast, after $48 \mathrm{~h}$ of Dex induction, MCF-7TG cells showed a gradual disappearance of $\mathrm{G}_{1}$-phase cells and a corresponding accumulation of S-phase cells. After $96 \mathrm{~h}$ of induction, the increase in the S-phase population $(37.20 \%)$ and decrease in the number of $\mathrm{G}_{1}$ phase cells $(60.53 \%$ $\mathrm{G}_{1} / \mathrm{G}_{0}$ cells) and $\mathrm{G}_{2} / \mathrm{M}$-phase cells $(2.45 \%)$ were even more marked (Figure 6).

\section{A}

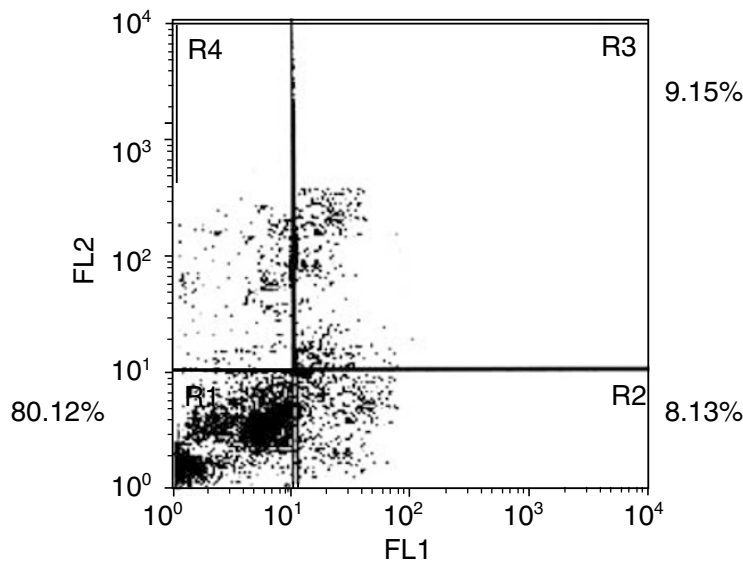

B
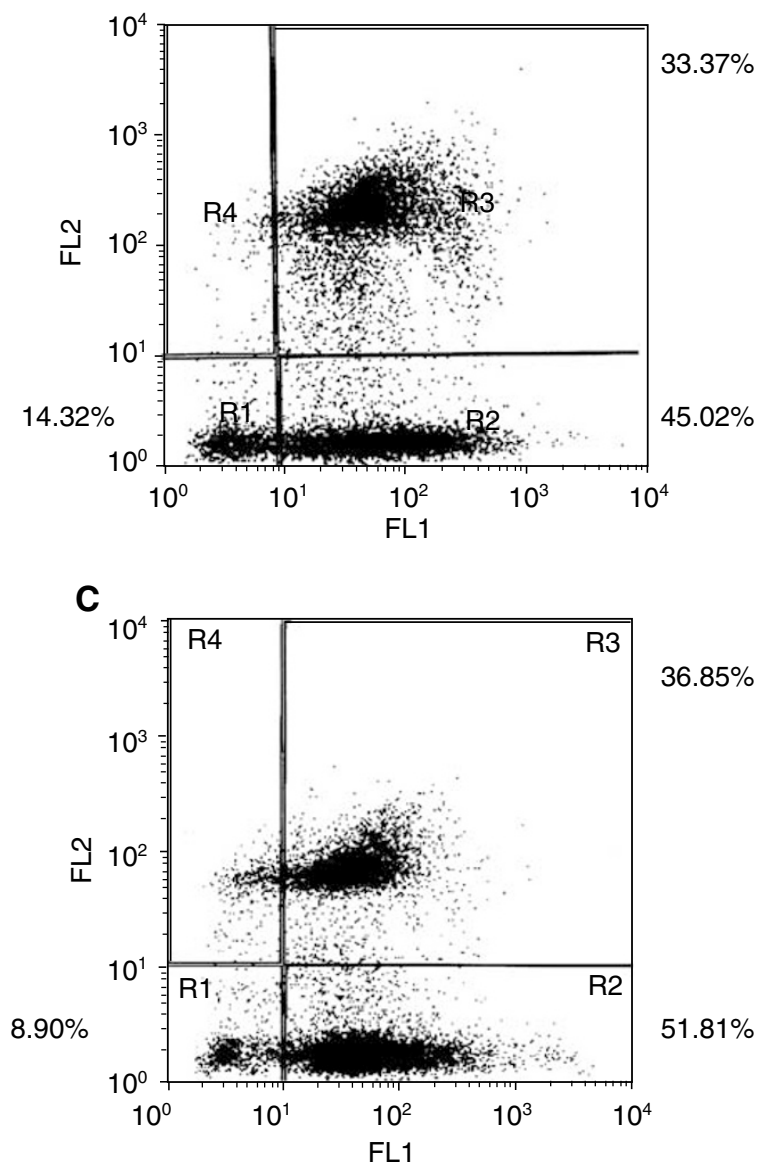

Figure 3 Quantification of gef-induced apoptosis in MCF-7TG cells by fluorescence-activated cell sorting analysis. Cells were stained with annexin $\mathrm{V}$ and $\mathrm{Pl}$ to evaluate apoptotic cell death, as described in Materials and Methods. (A) MCF-7 cells. (B) MCF-7TG cells after $48 \mathrm{~h}$ of induction with Dex. (C) MCF-7TG cells after $96 \mathrm{~h}$ of induction with Dex. The data shown are representative of three separate experiments.

\section{DISCUSSION}

We demonstrate for the first time that transfection of the gef gene makes it possible to decrease tumour cell growth in breast cancer cell line MCF-7. Our system is independent of the administration of a prodrug, which is required in systems such as Herpes simplex virus thymidine kinase and cytosine deaminase (Greco and Dachs, 

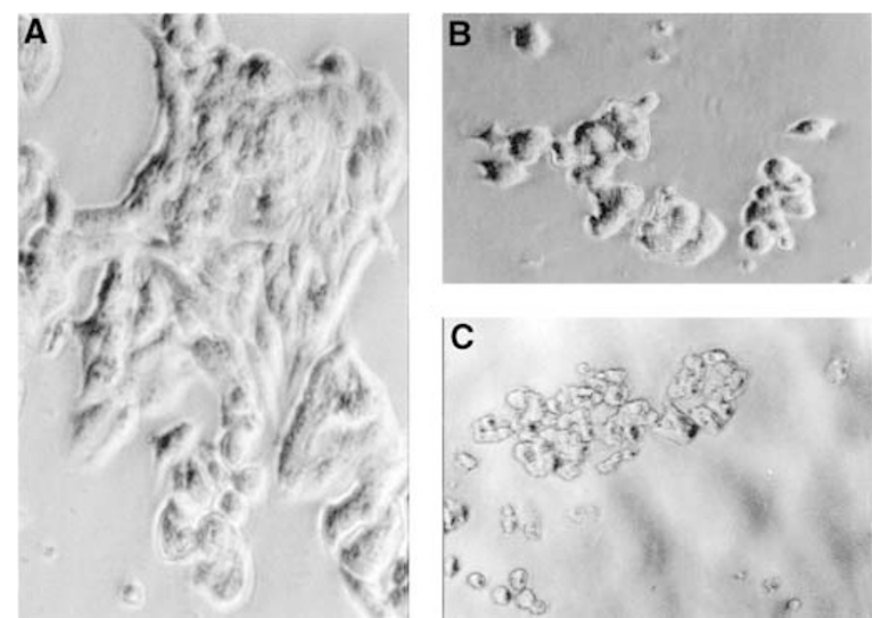

Figure 4 Phase contrast micrographs of parental and transfected MCF-7 cells. Parental MCF-7 cells, grew in clumps, were typically polygonal in outline $(\times 40)(\mathbf{A})$ and adhered strongly to the culture flask, whereas MCF7TG cells treated with Dex for $48 \mathrm{~h}(\times 40)(\mathbf{B})$ to induce gef gene expression were rounded and easily detached from the culture flask. These changes were more marked in MCF-7TG cells after $96 \mathrm{~h}$ of Dex induction $(\times 20)(\mathbf{C})$.
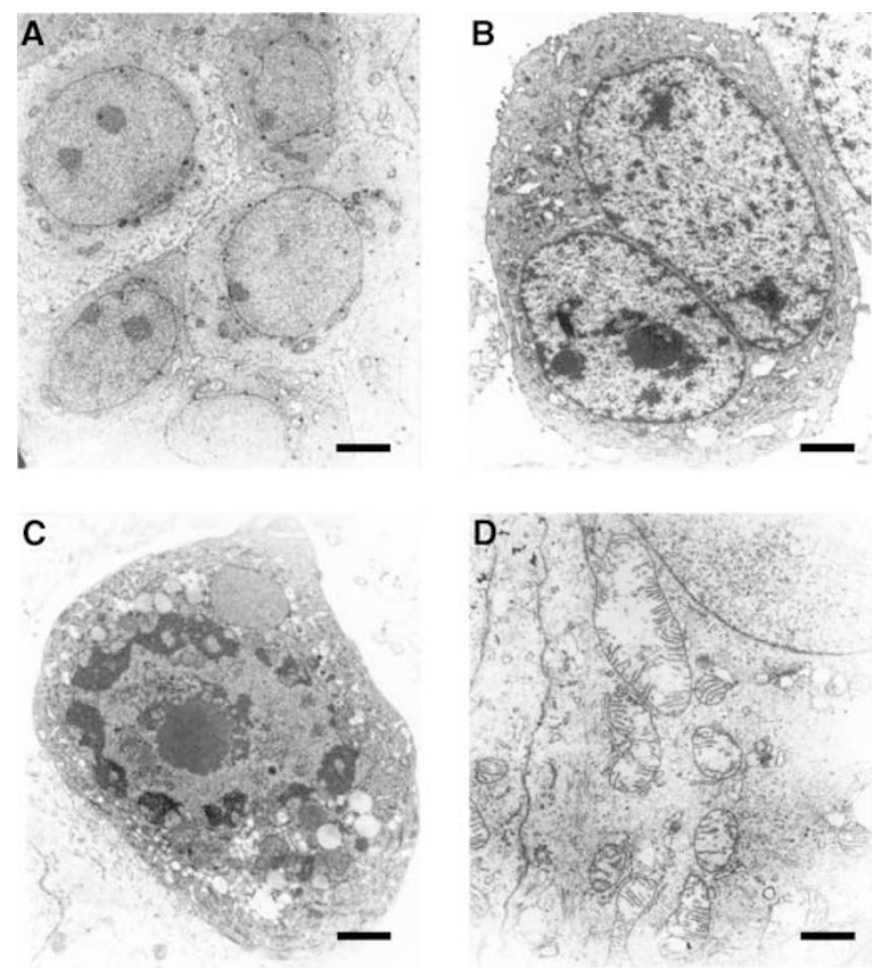

Figure 5 Ultrastructural morphology of MCF-7 and MCF-7TG cells treated with Dex to induce gef gene expression. (A) Typical morphology of MCF-7 parental cells demonstrated light cytoplasmic complexion $(\times 2500)$. (B) MCF-7TG cell with condensed granular-appearing chromatin $(x 4000)$. (C) Dying MCF-7TG cell with a convoluted nuclear membrane. The masses of compact chromatin are highly electron dense and homogeneous in texture. Note mininuclei with a different chromatin pattern ( $\times$ 6300). (D) Detail of cytoplasm of an MCF-7TG with mitochondrial dilation $(\times 8000)$. Scale bars: $(\mathbf{A}) 2.4 \mu \mathrm{m}$; $(\mathbf{B}) 1.5 \mu \mathrm{m} ;(\mathbf{C})$ $0.9 \mu \mathrm{m} ;$ (D) $0.75 \mu \mathrm{m}$.

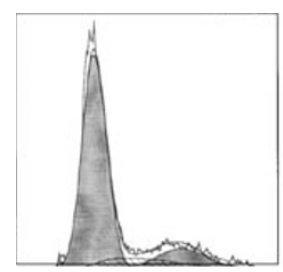

A: G0-G1: $74.98 \%$ $\mathrm{S}: 12.83 \%$ G2-M: $12.19 \%$
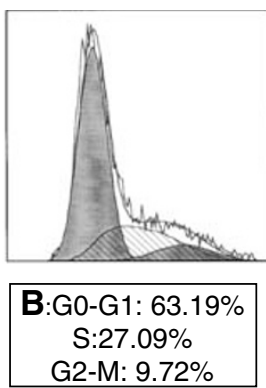

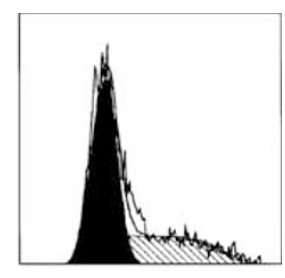

C:G0-G1: $60.35 \%$ S: $37.20 \%$ G2-M: $2.45 \%$
Figure 6 FACScan analysis of the cell cycle. MCF-7 and MCF-7TG cells treated with Dex were harvested and analysed to distinguish populations of cells in different phases of the cycle, as described in Materials and Methods. (A) Parental MCF-7 cells. (B) Transfected MCF-7TG cells after $48 \mathrm{~h}$ of Dex induction. (C) Transfected MCF-7TG cells after $96 \mathrm{~h}$ of Dex induction.

2001), and which may present problems related to general toxicity, drug release and bioviability.

The use of genes that damage tumour cells and do not require a prodrug is one of the aims of new gene therapy strategies. Recently, some procaryotic and viral genes have been shown to be able to induce tumour cell death (Martin et al, 2000; Zhuang et al, 1995; Paulus et al, 1997). In this connection, the gef gene shows a killing function in procaryotic cells, which may be modulated by the action of different promoters (Molin et al, 1993). The product of the gef gene is a cytoplasmatic membrane protein whose $19 \mathrm{~N}$ terminal hydrophobic amino acids constitute a membranespanning segment, probably in the form of an alpha-helix structure that anchors the protein to the membrane. The C-terminal part, localised in the periplasm in dimeric form, encodes the toxic domain (Poulsen et al, 1991). We used a eucaryotic expression vector that includes the MMTV promoter to obtain a construction with the gef gene. Transfection of this construct into MCF-7 cells and the induction of these tumoral cells with Dex led to a marked decrease in the rate of cell growth in MCF-7TG cells in comparison with parental MCF-7 cells. This finding suggests that the gef gene has an antiproliferative effect on breast cancer cells.

Although the gef gene showed considerable cytotoxic effects in MCF-7 cells, it is not clear how this gene inhibits growth of these tumour cells. Nonmammalian genes may act through different mechanisms when they are introduced and expressed in tumour cells. However, the induction of apoptosis in tumour cells is a frequent mechanism of cell damage. Gene therapy strategies based on the use of diphtheria toxin A gene (Paulus et al, 1997) have achieved complete inhibition of protein synthesis in glioblastoma cells. The chicken anaemia virus-derived protein VP3 (apoptin) is able to induce programmed cell death in transformed and malignant cells, including osteosarcoma cells (Zhuang et al, 1995; Pietersen et al, 1999). In melanoma, tranfection of the transcription factor E2F-1 induced apoptosis in the tumoral cell lines SK-MEL-28 and SK-MEL-2 (Dong et al, 1999). To determine whether apoptosis is also the mechanism by which the gef gene induces cytotoxicity, MCF-7TG cells were stained with annexin V and PI, and examined with fluorescence-activated cell sorting. These studies clearly demonstrated that cytotoxicity was the result of induction of apoptotic cell death. However, apoptosis was clearly demonstrated after $48 \mathrm{~h}$ of induction, in contrast to what has been observed in procaryotic cells such as Pseudomonas putida (Ronchel et al, 1998). In procaryotic cells, widespread cell death occurred $7 \mathrm{~h}$ after induction. This may reflect structural and functional differences between human and bacterial cell membranes or to the need for a target amount of Gef protein in the eucaryotic cells. This latter requirement has been observed in procaryotic cells, in which a critical concentration of Gef protein (different from other killer proteins such as protein E) was needed 
to provoke cell death (Ronchel et al, 1998). In MCF-7TG, apoptosis was confirmed in electron microscopic images. The most significant finding was the compaction and marginalisation of chromatin at the nuclear periphery, which is a cytological hallmark of apoptosis (Kerr et al, 1995). Similar changes have been observed during apoptotic cell death in MCF-7 cells transfected with antisense Hsp70 cDNA (Nylandsted et al, 2000).

In procaryotic cells, it has been shown that the product of the gef gene is anchored to the cell membrane, where it diminishes the membrane potential and leads to membrane leakiness, which in turn results in the efflux of cellular $\mathrm{Mg}^{2+}$ and the influx of periplasmic molecules (Gerdes et al, 1986). This mechanism induces morphological changes in cells, which subsequently undergo cell death (Ono et al, 1987). The specific mechanisms of action of the gef gene in eucaryotic cells have not been elucidated. Nonetheless, two of our findings stand out. Firstly, cell cycle analysis in MCF-7TG cells suggested that gef gene expression is associated with aberrant cell cycle control characterised by premature progression from $G_{1}$ to $S$ phase and $G_{2}$ delay. The results of cell cycle analysis are consistent with those in other tumour cell lines in which apoptotic mechanisms have been induced (Wei et al, 1998). Since they are unable to accomplish normal mitosis, these cells do not proliferate, and apoptotic cell death is induced. Secondly, we also observed a typical pattern of mitochondrial dilation that was always present in all MCF-7TG cells analysed after gef expression was induced. This finding may be related to the induction of apoptosis by the gef gene, and may also be related to the alteration in mitochondrial membranes, which has been demonstrated to be a critical step in several apoptotic pathways (Boya et al, 2001). However, although numerous models of apoptosis have been described in tumour

\section{REFERENCES}

Boya P, Roques B, Kroemer G (2001) New EMBO members' review: viral and bacterial proteins regulating apoptosis at the mitochondrial level. EMBO J 20: 4325 - 4331

Dong YB, Yang HL, Elliot MJ, Liu TJ, Stilwell A, Atienza C, McMaster KM (1999) Adenovirus-mediated E2F-1 gene transfer efficiently induces apoptosis in melanoma cells. Cancer 86: $2021-2033$

Favrot M, Coll JL, Louis N, Negoescu A (1998) Cell death and cancer: replacement of apoptotic genes in inactivation of death suppressor genes in therapy. Gene Ther 5: 728-739

Gerdes K, Bech FW, Jorgensen ST, Lobner-Olesen A, Rasmussen PB, Atlung T, Boe L, Karlstom O, Molin S, Von Meyenburg K (1986) Mechanism of postsegregational killing by the hok gene product of the parB system of plasmid R1 and its homology with the relf gene product of the E. coli relB operon. EMBO J 5: $2023-2029$

Gerdes K, Poulsen LK, Thisted T, Nielsen AK, Martinussen J, Anderssen PH (1990) The hok killer gene family in Gram negative bacteria. New Biologist 2: $964-956$

Greco O, Dachs GU (2001) Gene directed enzyme/prodrug therapy of cancer: historical appraisal and future perspectives. J Cell Physiol 187: $22-36$

Hart RI (1996) Tissue specific promoters in targeting systemically delivered gene therapy. Semin Oncol 23: $154-158$

Kerr JFR, Gobé GC, Winterford CM, Harmon BV (1995) Anatomical methods in cells death. Methods Cell Biol 46: 1-27

Marchisone C, Pfeffer U, Del Grosso F, Noonan F, Sant DM, Albini A (2000) Progress towards gene therapy for cancer. J Exp Clin Cancer Res 19: $261-270$

Martin V, Cortés ML, De Felipe P, Farsetti A, Calcaterra NB, Izquierdo M (2000) Cancer gene therapy by thyroid hormone-mediated expression of toxin genes. Cancer Res 60: 3218-3224

Molin SL, Boe LB, Jensen CS, Kristensen M, Givskov M, Ramos JL, Bej AK (1993) Suicidal genetic elements and their use in biological containment of bacteria. Annu Rev Microbiol 47: 139-166

Nylandsted J, Rohde M, Brand K, Bastholm L, Elling F, Jäättelä M (2000) Selective depletion of heat shock protein 70 (Hsp70) activates a tumor- cells (e.g., calcium-binding proteins, protein kinases, nuclear transcription factors, oncogenes and cysteine proteases) (Rowan and Fisher, 1997; Favrot et al, 1998), the pathway by which the gef gene acts in MCF-7 cells presently remains under investigation.

To our knowledge, this is the first demonstration that the gef gene, which has a killing function in E. coli, significantly impairs proliferation in tumoral MCF-7 cells derived from breast cancer. Although the mechanism remains unknown at present, it is clear that the product of the gef gene induces cellular modifications that are representative of apoptosis in these tumour cells. Our results suggest that the gef gene can be considered a possible candidate for a new gene therapy strategy, which is simpler than other killersuicide systems because it does not require the use of a prodrug. The possibility of using selective transcriptional control sequences with gef therefore offers the gene therapist a tool of significant potential. We are carrying out experiments in mice and in other tumoral cells which can determine the effectiveness of this new cancer therapy approach.

\section{ACKNOWLEDGEMENTS}

We thank Jaime Lazuen Alcón (Technical Services, University of Granada) for flow cytometry analyses, and David Porcel Muñoz and Concepción Hernandez Castillo (Technical Services, University of Granada) for electronic microscopy images. Appreciation is expressed to MC Ronchel of the Estación Experimental del Zaidín (CSIC) in Granada for help with construction of the vector, and $\mathrm{K}$ Shashok for improving the use of English in the manuscript. specific death program that is independent of caspases and bypasses Bcl2. Proc Natl Acad Sci USA 97: 7871-7876

Ono K, Akimoto S, Ohnishi Y (1987) Nucleotide sequence of the pnd gene in plasmid R483 and role of the pnd gene product in plasmolysis. Microbiol Immunol 31: 1071 - 1083

Paulus W, Baur I, Oberer DM, Breakefield XO, Reeves AA (1997) Regulated expression on the diphtheria toxin A gene in human glioma cells using prokaryotic transcriptional control elements. J Neurosurg 87: $89-95$

Pietersen AM, Vander Erb MM, Rademaker HJ, Vander Wollenberg DJ, Rabelink MJ, Kuppen PJ, Van Dierendonk JH, Van Ormondt H, Masman D, Van de Verde CJ, Van der Eb AJ, Hoeben RC, Noteborn MH (1999) Specific tumor-cell killing with adenovirus vector containing the apoptin gene. Gene Therapy 6: 882-892

Poulsen LK, Larsen NW, Molin S, Andersson P (1992) Analysis of an Escherichia coli mutant strain resistant to the cell-killing function encoded by the gef gene family. Mol Microbiol 6: 895-905

Poulsen LK, Refn A, Molin S, Andersson P (1991) Topographic analysis of the toxic Gef protein from E. Coli. Mol Microbiol 5: 1639-1648

Prados J, Melguizo C, Aranega AE, Escobar-Jimenez F, Cobo V, Gonzalez R, Aránega A (1995) Circulating alpha-actin in non-insulin-dependent diabetics with autonomic dysfunction. Int J Cardiol 51: 127-130

Prados J, Melguizo C, Marchal JA, Vélez C, Álvarez L, Aránega A (1998) Therapeutic differentiation in human rhabdomyosarcoma cell line selected for resistance to actinomycin D. Int J Cancer 75: 379-383

Pützer BM, Stiewe T, Crespo F, Esche H (2000) Improved safety through tamoxifen regulated induction of cytotoxic genes delivered by Ad vectors for cancer gene therapy. Gene Therapy 7: 1317-1325

Ronchel MC, Molina L, Witte A, Lutbiz W, Molin S, Ramos JL, Ramos C (1998) Characterization of cell lysis in Pseudomonas putida induced upon expression of heterologous killing genes. Appl Environ Microbiol 64: $4904-4911$

Ronchel M, Ramos JL (2001) Dual system to reinforce biological containment of recombinant bacteria designed for rhizoremediation. Appl Environ Microbiol 67: 2649-2656 
Rowan S, Fisher DE (1997) Mechanism of apoptotic cell death. Leukemia 11: $457-465$

Sambrook J, Fritsch EF, Maniatis T (1989) In vitro amplification of DNA by the polymerase chain reaction. Molecular cloning. In A Laboratory Manual, Nolan C, (ed) pp 14.18-14.19. New York: Cold Spring Harbor Laboratory Press

Shangara L, Ulrich ML, Dietrich N, James FB, Schlegel PG (2000) Suicide genes therapy: past, present and future perspectives. Immunol Today 21: $48-54$

Shillitoe EJ, Noonan S (2000) Strength and specificity of different gene promoters in oral cancer cells. Oral Oncol 36: 214-220
Villalobos M, Olea N, Brotons JA, Olea-Serrano MF, Ruiz de Almodóvar JM, Pedraza V (1995) The E-Screen assay: a comparison of different MCF-7 cell stocks. Env Health Perspect 9: 844-849

Wei SJ, Chao Y, Hung YM, Lin WC, Yang DM, Shih YL, Ch'ang LY, WhangPeng J, Yang WK (1998) S- and G2-phase cell cycle arrests and apoptosis induced by ganciclovir in murine melanoma cells transduced with herpes simplex virus thymidine kinase. Exp Cell Res 241: 66-75

Zhuang SM, Shvarts A, Ormondt HV, Jochemsen AG, Vander EB, Noteborn M (1995) Apoptin, a protein derived from chicken anemia virus, induces p53-independent apoptosis in human osteosarcoma cells. Cancer Res 55: 486-489 